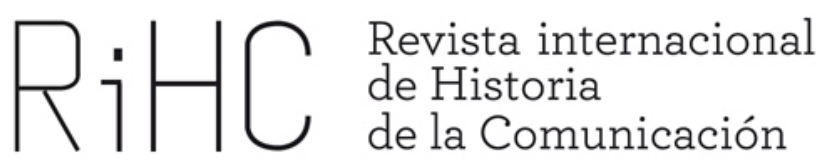

\title{
LAS TIRAS DE PRENSA NORTEAMERICANAS DE FINALES DEL SIGLO XIX Y PRINCIPIOS DEL SIGLO XX COMO REFLEJO DE LA SOCIEDAD ${ }^{1}$
}

DOI: http://dx.doi.org/10.12795/RiHC.2014.i03.02

Francisco Saez de Adana Herrero Investigador Colaborador del Instituto de Estudios Norteamericanos, Universidad de Alcalá

Departamento de Comunicación, Universitat Pompeu i Fabra

kiko.saez@uah.es

Recibido: 1-10-2014

Aceptado: 10-11-2014

Resumen: En este trabajo se analiza el papel de las tiras de prensa publicadas en los periódicos norteamericanos desde finales del siglo XIX hasta mediados del siglo XX como representación, a través de la ficción, de la sociedad estadounidense de la época. Se muestra la capacidad de este medio de expresión, utilizado como entretenimiento de un público mayoritario, para transmitir las inquietudes de dicha sociedad. Se analizan, entre otros, aspectos como la creación de una nueva sociedad urbana, la nostalgia de la frontera o los efectos de la Gran Depresión.

\footnotetext{
${ }^{1}$ Este trabajo ha sido posible gracias a la Beca Benjamin Franklin concedida por el Instituto Franklin de Investigación en Estudios Norteamericanos de la Universidad de Alcalá.
} 
Palabras clave: Tiras de prensa, sociedad norteamericana, historia cultural

\begin{abstract}
The role of the newspaper strips published in American newspapers from the end of the $19^{\text {th }}$ century to the middle of the $20^{\text {th }}$ as reflection, through the fiction, of the United States society of that age is analyzed in this work. The capability of this medium of expression, used as entertainment for a major audience, to transmit the concerns of that society is shown. Aspects as the creation of a new urban society, the nostalgia of the border of the effects of the Great Depression are analyzed among others.

Keywords: Newspaper strips, American society, cultural history
\end{abstract}

\title{
1 Introducción
}

En octubre de 1989, expertos de varios países se reunieron en el Salón Internacional de Lucca en Italia, para determinar el origen del cómic. Prácticamente por unanimidad dicho origen se dató en 1896 con la aparición de The Yellow Kid en las páginas de The New York World editado por Joseph Pulitzer. El carácter discutible de dicha decisión, obviando por ejemplo el trabajo de Rodolphe Topffer (que algunos autores como William Kuskin consideran no sólo el padre del cómic, sino de la novela gráfica, término por lo demás también bastante discutible (como se puede ver en Barrero et al., 2013) en la primera mitad del siglo XIX, sirvió como excusa para poder celebrar el centenario del cómic como medio en el año 1996, tratando de dar cierta notoriedad a esta forma de expresión y, en cierta manera, tratando de igualarlo con el cine cuya fecha de nacimiento parece más clara. Como se ha comentado, marcar The Yellow Kid como inicio del cómic como arte puede ser discutible (Smolderen, 2009), pero dicha efemérides puede servir para marcar el comienzo del mismo como medio de comunicación ligado a su publicación en la prensa norteamericana, aspecto que centra el interés de este artículo. Como bien afirma Walter Benjamin, la obra de arte se ve mediada por las condiciones de producción (1973: 18). Y el hecho de que el cómic encontrara en los periódicos su medio de difusión durante mucho tiempo, condicionó el carácter del cómic como arte, ya que impuso unas condiciones de formato y periodicidad ligadas a dicho medio de publicación. Como afirma Iván Pintor "las viñetas ofrecen un espacio privilegiado para recuperar la memoria" (2014), aspecto que se pone de manifiesto repetidamente en las manifestaciones más recientes de este arte (ejemplos como los de Joe Sacco, Art Spiegelman o Guy Deslile que tan bien recoge el propio Pintor), pero que nace en el cómic de prensa publicado en la primera mitad del siglo XX.

El objetivo de este artículo es hacer un recorrido por los primeros cómics de prensa mostrando fundamentalmente su carácter de imagen de la historia y, más concretamente, de la sociedad norteamericana de su época. Se trata de poner de 
manifiesto el carácter del cómic de prensa como medio de transmisión de la historia, especialmente en las primeras manifestaciones de dicho arte. La forma de reproducción, citando de nuevo a Benjamin, en forma de tiras diarias o planchas dominicales, condicionará al cómic al publicarse junto a las noticias de la época y, además, siendo la prensa uno de los principales medios de entretenimiento durante esos años, por su capacidad para llegar a millones de lectores de todas las edades y condiciones sociales. El cómic, como la mayor parte de las obras de arte, es un reflejo de la sociedad en la que se desarrolla. Sin embargo, su publicación en prensa, acentúa aún más su carácter social e histórico. El carácter temporal de su publicación, el hecho de que fueran publicados diariamente o semanalmente condicionaba la experiencia lectora $y$, sobre todo, ligaba estas obras al tiempo. Sin embargo, esta publicación periódica, no es el único motivo para ese carácter histórico, ya que dicha periodicidad ya se producía en otras manifestaciones de la cultura popular como el folletín. De esta forma, el cómic encuentra una ligazón aún mayor con la temporalidad, debido a su publicación junto a los acontecimientos sociales e históricos, que hace que se convierta en un medio ideal para el reflejo de dichos acontecimientos, como ya han señalado otros estudios con respecto al humor gráfico (Gregório, 2007; Hampton, 2013; Peñamarín, 2012). Este artículo mostrará cómo el pensamiento y la sociedad norteamericana se ven reflejados en esos primeros cómics de prensa y, no sólo en el humor gráfico como demuestran los estudios anteriormente mencionados.

La metodología empleada ha sido un análisis lo más exhaustivo posible de las diferentes tiras de prensa publicadas en este período, fundamentalmente, a través de las reediciones que se han llevado a cabo en los últimos años, gracias al esfuerzo de varias editoriales por recuperar el patrimonio de la historieta. También se han analizado dichas páginas accediendo a sus publicaciones originales en prensa conservadas en el Billy Ireland Cartoon Library \& Museum, durante una estancia de investigación realizada en abril de 2014. Entre todo el material consultado, se han seleccionado varias tiras que se presentan en este artículo, como ejemplos representativos del reflejo del pensamiento y de la sociedad norteamericana de la época, que es la tesis principal de este artículo. Se muestran una gran profusión de ejemplos, para subrayar esa idea de que la tesis mencionada es un fenómeno extensivo a lo largo del cómic de prensa de esta época. Esta gran variedad de casos puede resultar en un análisis menos profundo de cada uno de ellos, pero se considera interesante con el fin de demostrar lo extendido del fenómeno estudiado. Esto no quiere decir que estos casos sean los únicos. Sin embargo, ha sido necesaria una labor de selección para encontrar el equilibrio entre la idea de demostrar la tesis con un número suficiente de ejemplos y respetar una extensión razonable para el artículo y un nivel de análisis suficiente para cada uno de ellos.

Existen otros trabajos en la literatura cuyo objetivo es utilizar el cómic para estudiar la sociedad contemporánea. Algunos de ellos, referentes al humor gráfico, ya se han 
mencionado anteriormente. Otros ejemplos pueden ser Costello (2009), donde se estudia la América de la Guerra Fría, Frezza (2009) que trata de la guerra y la posguerra en la ciencia ficción contemporánea o Rodríguez Moreno (2010) sobre la producción de la editorial Timely durante la Segunda Guerra Mundial. Este artículo pretende contribuir a la literatura con el análisis de la Norteamérica de los primeros años del siglo XX y su relación con el cómic de prensa.

Para el lector no iniciado es interesante indicar qué es el cómic de prensa también conocido como tira de prensa. Una tira de prensa es un cómic que se publica en los periódicos en los que se recoge bien una secuencia cómica o bien una narrativa serializada. Las tiras de prensa muestran dos diferentes formas: por un lado, tenemos la tira propiamente dicha, de forma horizontal, en blanco y negro que se publica tradicionalmente de lunes a sábado y, por otro, la página dominical a todo color, generalmente publicada en suplementos especiales que aparecen obviamente los domingos y que, dada su extensión, permite ofrecer secuencias de la historia más largas. Las tiras de prensa pueden mostrar una historia autoconclusiva en cada secuencia diaria, cosa que, generalmente sucede con las tiras humorísticas o pueden establecer una continuidad a través de la serialización, continuando la historia del día anterior, situación que se da, generalmente, en las denominadas tiras de aventuras, aunque esta correspondencia entre el género y el tipo de tira no es exclusiva. Es importante reseñar la publicación de las tiras junto a los periódicos, como ya se ha comentado, elemento que es tradicional en Estados Unidos a lo largo de todo el siglo $X X$. Este fenómeno se dará también, aunque en menor medida, en Europa. Sin embargo, en ocasiones, especialmente en el caso europeo, se pueden encontrar tiras en otros medios de comunicación como revistas o magazines, en donde, dada la cadencia de publicación cambia el modelo de publicación pudiéndose publicar tanto tiras horizontales como páginas a color sin mantener, obviamente, la cadencia diaria o semanal que supone la publicación en periódicos. Más información sobre el cómic de prensa se puede encontrar en Guiral, 2007; Harvey, 1995; Harvey, 2009; Horn, 1984; Steranko, 1970; y Trabado, 2012.

\section{De The Yellow Kid a Little Nemo in Slumberland. La infancia como reflejo de la sociedad}

El personaje de The Yellow Kid apareció por primera vez el 5 de mayo de 1895 en las páginas de una serie llamada Hogan's Alley creada por Richard F. Outcault e inscrita dentro del suplemento dominical creado por Pulitzer para The New York World en 
1889. Pulitzer se dio cuenta que la inclusión de dibujos en su periódico aumentaba las ventas del mismo, ya que completaba el carácter de entretenimiento que los periódicos de la época debían tener para llegar a toda la familia. Sin embargo, como se ha comentado antes, no se considera el nacimiento del cómic hasta 1896, concretamente en el mes de mayo, cuando Outcault introduce en el camisón amarillo del personaje (rasgo distintivo del mismo, del que recibe su nombre) un texto que hace las veces de diálogo del personaje. Desde el principio, con o sin bocadillos, la página se convirtió tal y como afirma Guiral "en una representación burlesca de la [...] vida cotidiana de un barrio trabajador muy humilde en el que convivían personas de diversas razas" (2007: 31). El carácter de reflejo de una sociedad está fuertemente presente desde el principio. The Yellow Kid se convierte, prácticamente desde sus comienzos, pero principalmente desde la incursión del diálogo en la serie, en un personaje que mira fijamente al lector, interpretando los sucesos cotidianos para él. Se puede considerar que es el hombre del lector que, a través de las frases de su camisón ha convertido el dibujo de prensa, en algo más, en un medio a través del cual transmitir su mensaje, en un medio de comunicación al fin y al cabo. El impacto de The Yellow Kid fue tan importante, que los principales magnates de la prensa, el ya citado Pulitzer y William Randolph Hearst se disputaron la posibilidad de que el personaje apareciera en sus diarios estrella, el ya mencionado World y el New York Journal respectivamente, como puede verse en Blackbeard (1984), donde se manifiesta que durante un tiempo el personaje se publicó en ambos periódicos simultáneamente, tras una sentencia judicial resultado de un enfrentamiento jurídico entre los dos magnates de la prensa (un estudio más detallado sobre el periodismo norteamericano de la época puede verse en Campbell, 2006; Sánchez Aranda, 1998; Whyte, 2009). Este impacto y el carácter del cómic como medio de comunicación se manifiesta en la creación de un término, tal y como afirma Waugh, el del periodismo amarillo (1947: 1), que en sus comienzos describía el tipo de prensa que tanto Pulitzer como Hearst llevaban a cabo para magnificar los sucesos. Hasta ese momento los periódicos se editaban desde lo que se consideraba "un punto de vista caballeroso" (Waugh, 947: 7) reflejando las ideas de los lectores de clase alta, pero en ningún momento reflejando las de aquellos lectores más terrenales. El hecho de crear una prensa para este tipo de lector, y que, en dicho tipo de prensa, casualmente uno de sus elementos de éxito era la presencia (en ambos periódicos) de un chico amarillo que, por un lado, reflejaba las inquietudes del hombre de barrio, del americano medio, y que, además, había sido objeto de una cruenta lucha con el único fin de obtener más lectores, motivó que se escogiera el color amarillo para la creación de un término que ha sobrevivido hasta nuestros días.

Muchos otros cómics con niños se publicaron durante la época, entre las que merecen destacarse The Katzenjammer Kids creado en 1897 por Rudolph Dirks. Desde muy pronto los editores se dieron cuenta de que los cómics vendían periódicos y, una primera impresión (bastante parcial) era que los niños eran los principales lectores del 
suplemento de prensa. Hay que tener en cuenta que, en principio, los cómics sólo se publicaban como páginas dominicales a color (todavía no había aparecido la tira diaria), por lo que su carácter separado fomentaba esa lectura infantil. El éxito de The Yellow Kid empezó a cambiar un poco la dinámica, pero los primeros suplementos dominicales todavía están mayoritariamente poblados por personajes infantiles como los citados anteriormente, que muestran las vivencias de los chicos de barrio, como si el éxito de The Yellow Kid estuviera exclusivamente basado en su carácter infantil, circunstancia que en la mayor parte de las series, incluida la propia del chico amarillo, no era del todo cierta por la cantidad de consideraciones sociales de toda índole que dichas series incluían.

La mayor parte de estas series con niños como protagonistas mostraban un aspecto de la vida norteamericana muy cercano al que se ha comentado en The Yellow Kid: el chico de barrio que se cría en las calles de las incipientes ciudades norteamericanas. Hay que considerar que hasta ese momento, los cómics sólo entretenían a unos pocos millones de lectores que vivían dentro o alrededor de las grandes ciudades y que tenían acceso a los periódicos mencionados anteriormente. La época de la difusión masiva en todo el territorio estadounidense (y fuera de él) todavía no había llegado. Sin embargo, incluso en ese ámbito tan "limitado", una nueva clase social estaba apareciendo. El hombre de negocios norteamericano empezaba a vivir en los suburbios en casas situadas en filas una junto a otra como si de pequeñas plantaciones se trataran, dedicando parte de su vida diaria al trayecto de ida y vuelta a la ciudad donde realizaba su labor profesional. La familia era, como para toda la sociedad norteamericana, importante para esta nueva clase social y estos complejos residenciales pronto se llenaron de niños que, cada domingo, seguían el ritual de leer el suplemento dominical de los periódicos. Y esos niños no eran Yellow Kids de ninguna de las maneras. Y sobre todo sus padres no estaban cómodos con la imagen de la infancia que un personaje como The Yellow Kid transmitía. Otro tipo de personaje infantil era necesario. La Figura 1 muestra un ejemplo de plancha dominical de The Yellow Kid donde se ve una radiografía del comportamiento del chico de barrio con algunas actitudes poco educativas para el chico de la nueva clase media que vive en los suburbios. 


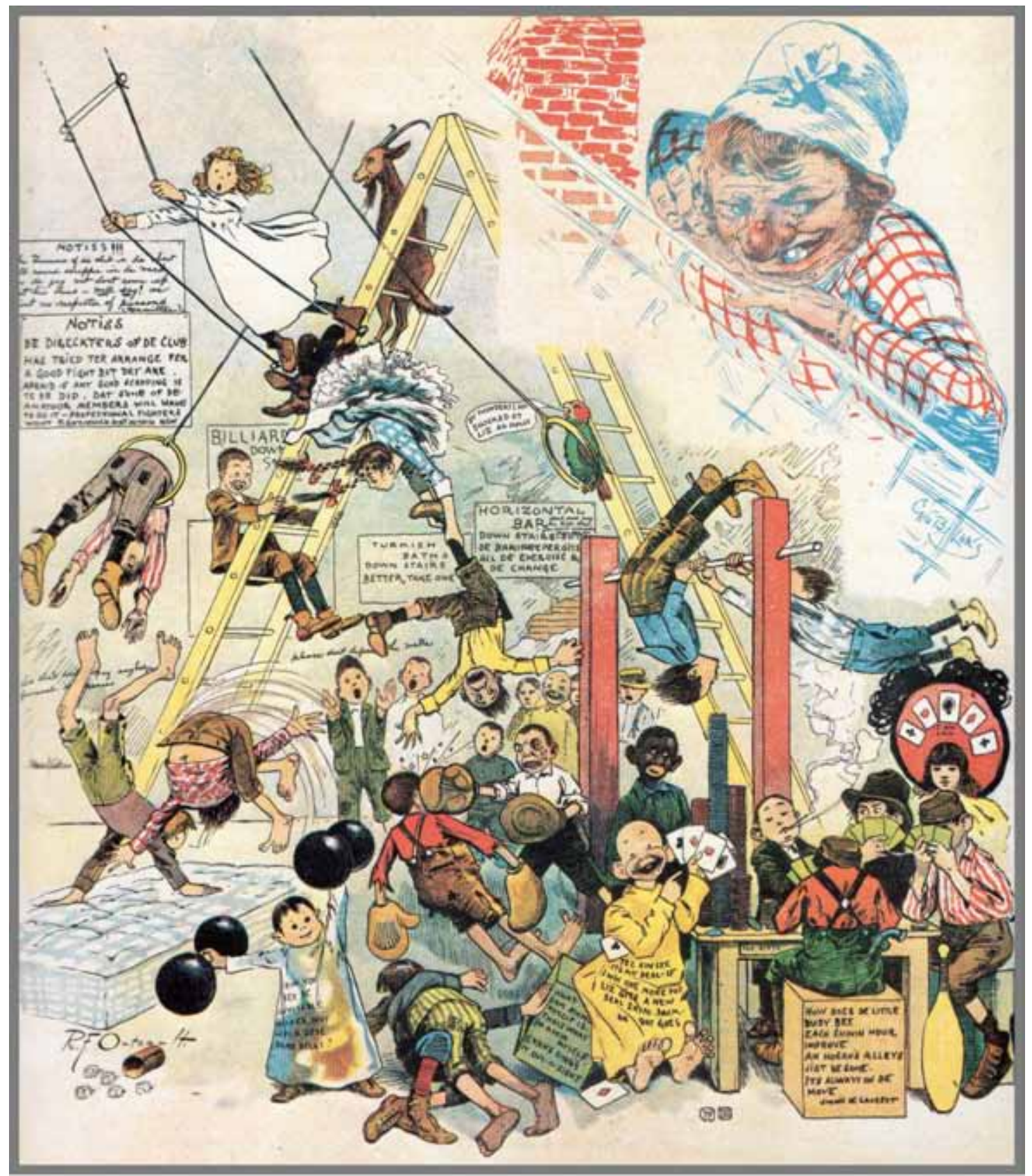

Figura 1. Página dominical de Hogan's Alley con la aparición de Yellow Kid del 27 de septiembre de 1896.

En esa circunstancia un personaje como Little Nemo nace para cubrir ese sector del entretenimiento infantil, aunque muy pronto demostró ser algo mucho más sofisticado. La serie Little Nemo in Slumberland fue creada por Winsor McCay en 1905 para The New York Herald. El mecanismo de la serie siempre es el mismo. El pequeño Nemo se acuesta en su cama en la primera viñeta para introducirse en el mundo mágico de Slumberland, donde cada domingo vivirá una aventura diferente (algunas de ellas con continuidad de una página dominical a otra), que siempre concluye con su despertar en la última viñeta de la página de cada domingo. Por tanto, se trata de una serie enmarcada en el mundo de los sueños, elemento que aprovecha su autor para dar rienda suelta a su imaginación construyendo un mundo de fantasía haciendo uso 
del tamaño que las enormes páginas dominicales de la época (de $40.6 \times 53.3 \mathrm{~cm}$ ) le permitían y del color en el que se reproducían dichas páginas. El elemento visual y de creación de lenguaje de Little Nemo ha sido ampliamente estudiado (Apolonides et al., 2005; Guiral, 2007; Horn, 1984; Steranko, 1970; Trabado, 2012), aunque este juego con el lenguaje visual será analizado aquí posteriormente desde otro punto de vista. Sin embargo, en este momento resulta de mayor interés el reflejo que, en la serie, aparece de la sociedad norteamericana de la época.

La huida que del mundo cotidiano propone Little Nemo cada domingo parece adecuada para satisfacer las necesidades de esas familias acomodadas de los suburbios, pero también constituye un reflejo del americanismo en los años 10 y 20. Thomas Hughes identifica americanismo con el desarrollo tecnológico de los inventores independientes como Nikola Tesla o Thomas Edison que desembocó en sistemas de producción como el fordismo y el taylorismo basados en los trabajos de Henry Ford y Frederick Winslow Taylor, sistemas sin los que de acuerdo a otros autores como Warren Susman, no se puede entender la cultura americana de la época. Se hace referencia a personajes que se constituían como figuras representativas del sueño americano, del modo de vida americano, acepciones que empiezan a ser acuñadas por otra parte en estos años. El trabajo de estos inventores independientes, como afirma el propio Hughes, se basa en una ruptura con la ciencia preestablecida, y un predominio de la imaginación y el instinto a la hora de desarrollar sus creaciones. Henry Ford es para muchos de estos autores el prototipo de héroe americano y la fundación de su fábrica en 1903 tendrá mucha influencia en la sociedad y la cultura posterior. Según Hughes "tanto Wright y Sullivan [...] fueron profundamente influidos por las filosofías de producción de los americanos Frederick W. Taylor y Henry Ford" (1987: 309), refiriéndose a los arquitectos Frank Lloyd Wright y Louis Henry Sullivan. Además, no solo "arquitectos del avant-garde trataron de expresar los valores de una era de entusiasmo tecnológico, sino también los pintores" (1987: 324). Se puede considerar que muchas de las páginas de Winsor McCay (como las que se muestran en las figuras) constituyen una mezcla de estas influencias junto con un carácter fuertemente freudiano que como el propio Susman empieza a ser una de las corrientes de pensamiento fundamentales en la vida norteamericana de la época. Por tanto, esta influencia tecnológica que se manifiesta en los sistemas de producción, basados en la creación y la imaginación, pero también en la funcionalidad, intervenían en el quehacer cotidiano del hombre de negocios de los suburbios, pero a su vez tenía un reflejo en el entretenimiento familiar que consumía esa nueva clase incipiente, siendo la obra de McCay un ejemplo de dicho reflejo. Las Figuras 2 y 3 muestran ejemplos de planchas dominicales de Little Nemo in Slumberland. Se puede observar el mestizaje entre una concepción freudiana junto con un tratamiento de la arquitectura similar al que Sullivan (Figura 4) y Wright (Figura 5) hacían en la época. 


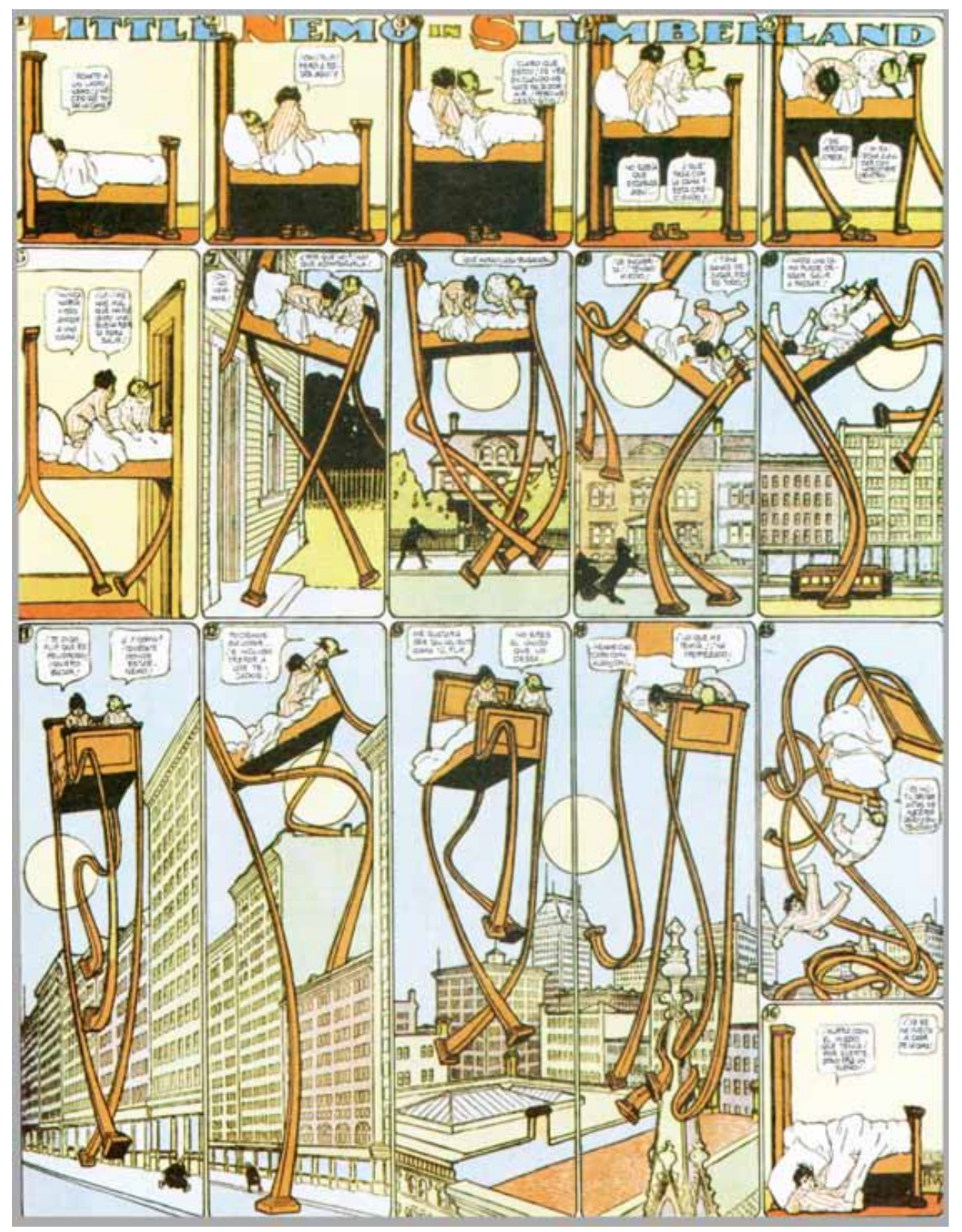

Figura 2. Página dominical de Little Nemo in Slumberland del 26 de julio de 1908. 


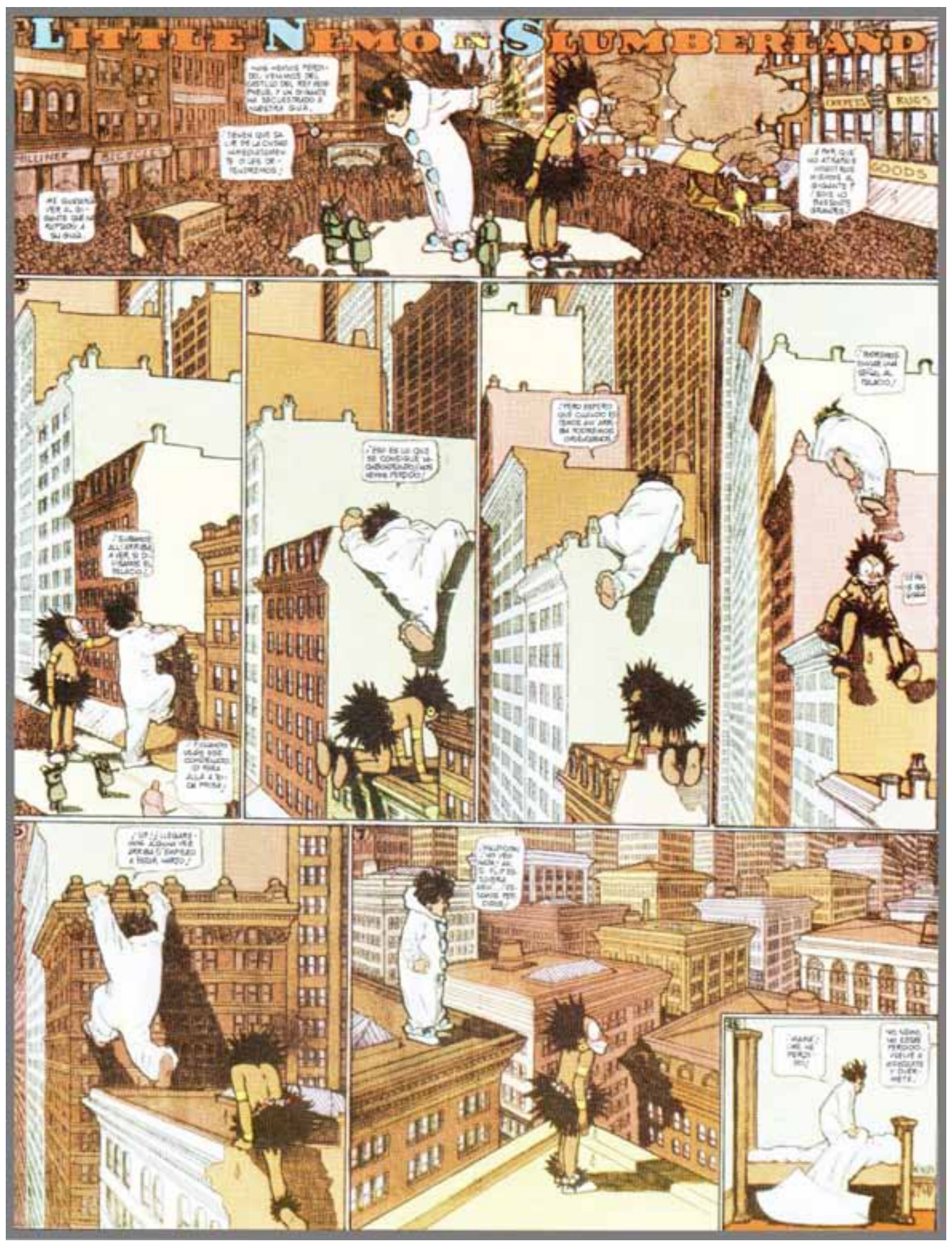

Figura 3. Página dominical de Little Nemo in Slumberland del 22 de septiembre de 1907. 


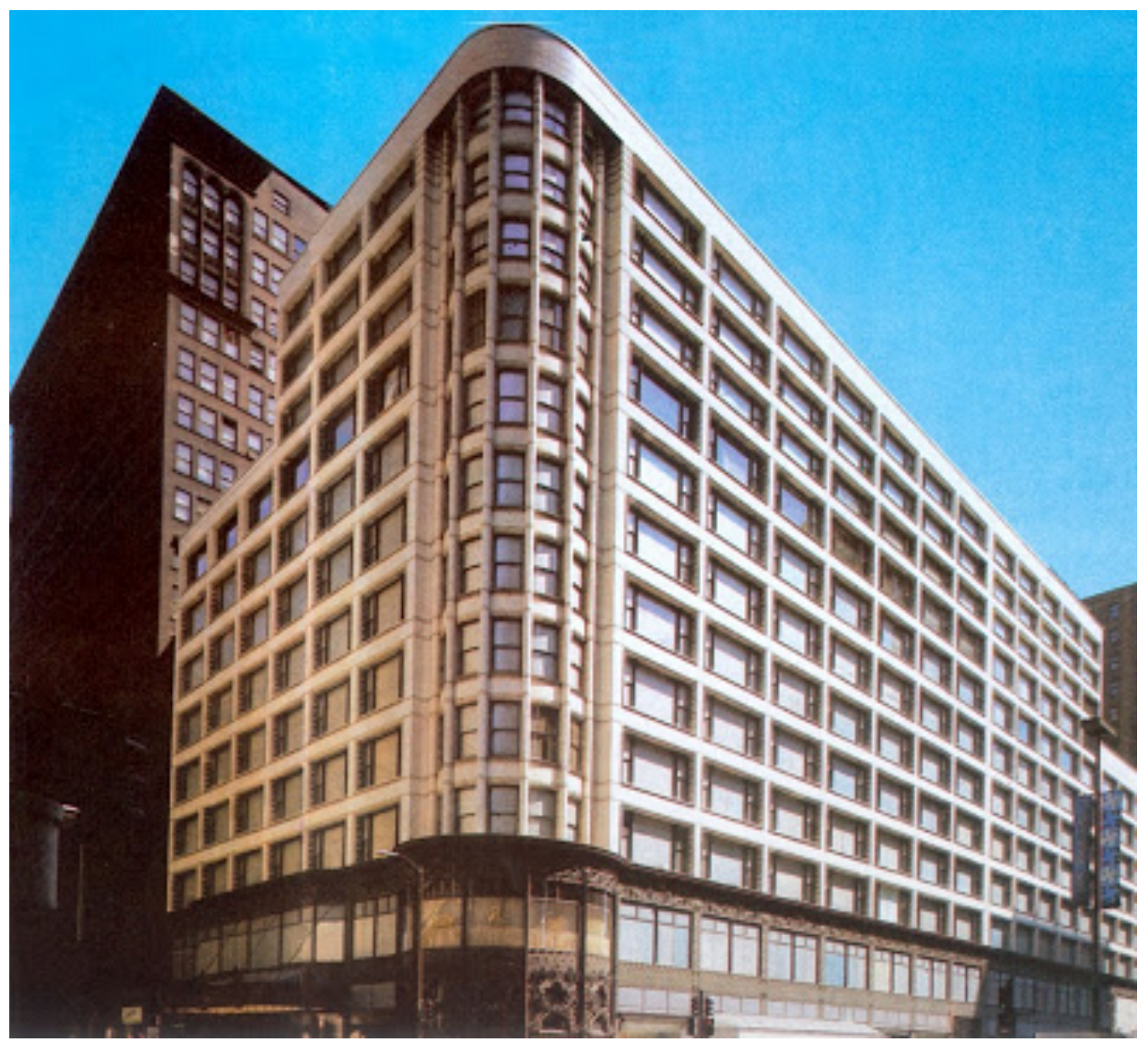

Figura 4. Arquitectura de Louis Henry Sullivan.

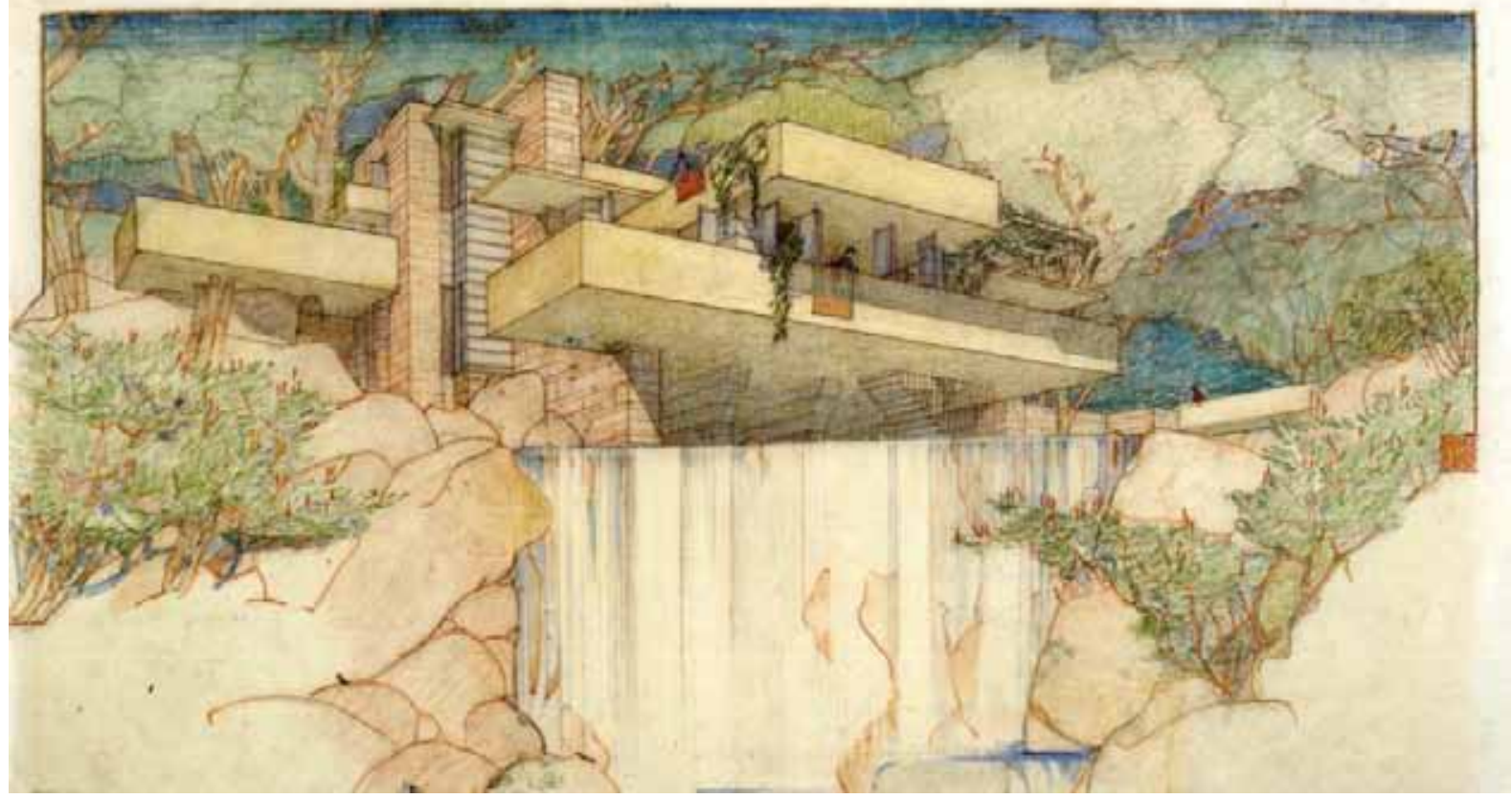

Figura 5. Arquitectura de Frank Lloyd Wright. 


\section{Krazy Kat o la obsesión por la libertad}

Si se mencionan los pioneros en el desarrollo del lenguaje del cómic, el ejemplo más claro de estos primeros años, junto a Little Nemo ya mencionado, es Krazy Kat. Krazy Kat fue creado en 1913 por George Herriman (dibujante de raza negra, aspecto bastante inusual en la época) para el New York Evening Journal de Randolph Hearst. Bajo el sencillo formato de las andanzas entre un gato y un ratón, Herriman desarrolla algo más complejo, en el que los papeles de gato y ratón están intercambiados, siendo el ratón la constante amenaza del gato, subyaciendo una historia amorosa, ya que el gato/gata (su sexo nunca queda muy claro) Krazy está enamorado del ratón Ignatz, pese al maltrato constante al que se ve sometido. Por otro lado, se crea un triángulo con la figura del perro policía encargado de proteger a Krazy de los continuos ataques de Ignatz, por medio del recursivo encarcelamiento de éste al final de muchas de las páginas dominicales. Lo más interesante de Krazy Kat es su juego del lenguaje, tanto a nivel visual, con la composición de página, la aparición de un metalenguaje o la consciencia en muchas de las páginas de la serie, por parte de los propios personajes, de encontrarse dentro de una página de cómic, como a nivel literario, con constantes juegos de palabras que hace que la serie sea, en ocasiones, muy difícil de entender en todos sus matices y que la traducción de la misma sea una tarea casi imposible, si se quieren conservar todos los significados del original.

José Manuel Trabado comenta, a raíz de los experimentos con el lenguaje del cómic tanto de Little Nemo como de Krazy Kat, que "sorprende comprobar cómo en los inicios de la creación de un lenguaje éste puede alcanzar la madurez de la autoconciencia" (2012: 141). Se hace referencia, en los dos casos mencionados anteriormente, a dos series creadas en los comienzos del lenguaje del cómic que, en lugar de dedicarse como elemento fundamental a contar una serie de aventuras de sus personajes, se dedican a explorar los límites narrativos de un nuevo medio, transcendiendo su misión inicial de entretener a los niños. Se crea un lenguaje totalmente adulto, ya que muy pronto, como recoge Waugh en su estudio, el número de lectores adultos empieza a superar al número de lectores infantiles, ya que éstos no son capaces de entender todo los juegos metaliterarios que existen en lo que aparentemente es una historia más del juego entre el gato y el ratón. Muy pronto, Krazy Kat se convierte en una serie seguida por muchos intelectuales de la época, de tal forma que su consideración como una forma elevada de arte hace que en 1922 sea adaptada en forma de ballet en New York, apartándola totalmente de su concepción infantil. Su hermanamiento con lo que en la época venía considerándose con la alta cultura, se manifiesta también en la comparación que John Alden Carpenter hace en el libreto de la adaptación, donde compara a Krazy con Don Quijote o Parsifal, considerando que todos ellos son los grandes optimistas de la literatura, destacando el carácter de optimismo de Krazy que no desfallece en su relación con Ignatz, incluso teniendo en cuenta que el sexo de ambos es un misterio en la serie. 
Volviendo al tema del lenguaje, es interesante la necesidad que existe de jugar con el lenguaje en los cómics de la época, aspecto que, como el propio Trabado recoge en su libro, no es exclusivo de los cómics y también aparece en otras formas artísticas de la época como la animación. En la obra de Trabado se recogen varios ejemplos del uso del metalenguaje y de la exploración de los límites narrativos, tanto en Little Nemo como en Krazy Kat, así como en obras de animación de la época, especialmente algunos cortos de los hermanos Fleischer. Este creciente interés se puede enlazar con la creación de una identidad americana. Según Susman los americanos de la época "eran constantemente y totalmente conscientes de que se encontraban en una nueva era" (1987: 108) uno de cuyas consecuencias fue "la creciente preocupación entre escritores, filósofos y estudiantes del lenguaje sobre la relación entre lenguaje y realidad" (1987: 110). El propio Susman no puede evitar ligar el enorme éxito de los juegos de palabras y crucigramas en la época, así como el interés en la obra de lingüistas como Alfred Korzybski, I.A. Richards, S.I. Hayakawa, Edward Sapir, Stuart Chase o Thurmond Arnold en una necesidad en encontrar no sólo lo que se debe comunicar, sino también una obsesión en cómo debe comunicarse. Así aparece una nueva manera de relacionarse con la realidad a través del lenguaje que Vachel Lindsay define como "civilización jeroglífica" (1915: 21), donde hay un ansia constante por entender, por tocar esta nueva realidad que se traduce en un incremento de la cultura visual y en el auge no sólo de la animación y el cómic, sino también del cine y el incremento exponencial de la publicidad visual. En este entorno, la plasticidad visual de autores como McCay o Herriman y su juego con un lenguaje en crecimiento, encuentra un caldo de cultivo ideal que les permite desarrollar sin ningún tipo de cortapisa su creatividad. La nueva sociedad norteamericana se apoya fundamentalmente en lo visual, pero es un lenguaje visual como búsqueda de la comprensión de la realidad y, sobre todo, de sus límites, límites que se exploran en las dos obras antes mencionadas. Hay que tener en cuenta que toda esta obsesión por el lenguaje coincide con la aparición del pensamiento freudiano en la vida intelectual americana, cuyas características son la liberación, la capacidad para la expresión individual y la necesidad de encontrar la belleza en el arte en contraposición al pensamiento puritano anterior encorsetado y hostil a la belleza y a la expresión de la misma. Esta aparición del pensamiento freudiano permite encauzar la obsesión por el lenguaje ya mencionada hacia nuevos medios de expresión basados en el surrealismo y con un fuerte componente onírico, elementos que son la base de las dos obras que se están mencionando. La Figura 6 muestra una página dominical de Krazy Kat donde se contrasta la libertad del paisaje fronterizo de las primeras viñetas, con la falta de libertad del único elemento urbano que aparece al final de la tira: la cárcel. 


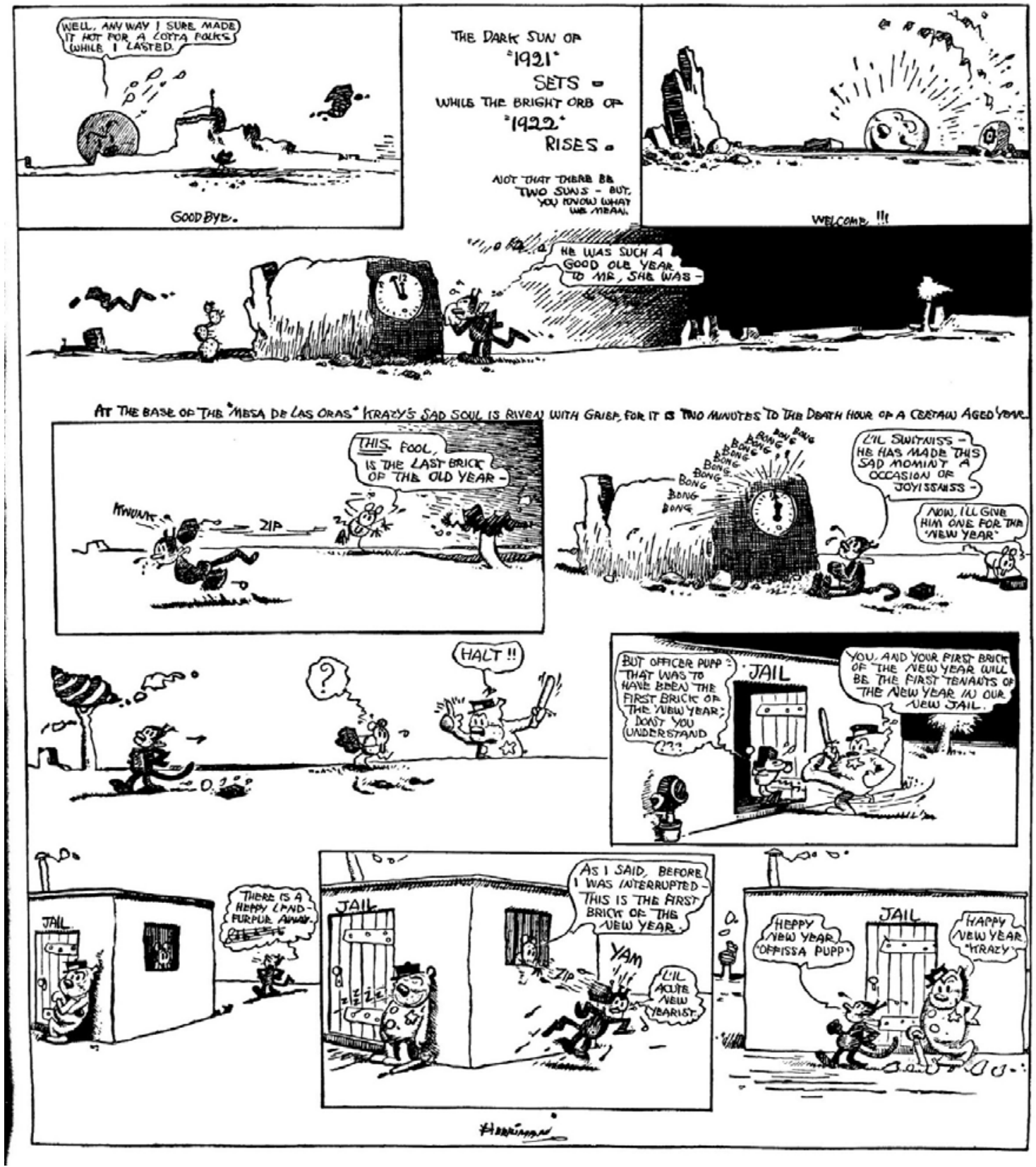

Figura 6. Página dominical de Krazy Kat del 1 de enero de 1922.

Otro elemento que es fundamental en Krazy Kat, en lo que se refiere a su relación con el pensamiento norteamericano de la época, y que no ha sido prácticamente analizado es el emplazamiento. En una serie que está constantemente en los límites entre lo realista y lo surrealista, resulta curioso que el emplazamiento tenga una situación geográfica tan concreta. Las andanzas de Krazy e Ignatz suceden en el condado de Coconino, en el estado de Arizona, curiosamente no muy alejadas geográficamente de la mayor parte de westerns de John Ford. De hecho, Herriman introduce en muchas ocasiones paisajes del Painted Desert o de Monument Valley que, aunque no pertenecen propiamente a ese condado, sirven para acentuar su visión romántica y 
estilizada de dicho territorio. Una de las razones de la elección de ese emplazamiento geográfico por parte de Herriman era su amor a dicho territorio, ya que pasaba la mayor parte de sus vacaciones en él. Pero obedece también a una fascinación que muchos intelectuales de la época como Waldo Frank o Lewis Mumford reconocen por el pasado americano y, fundamentalmente, por la frontera como elemento capital en la construcción de la sociedad norteamericana (Frank, 1929; Mumford, 1938). La creación de un nuevo modelo de sociedad, basado en la clase media que ya se ha mencionado, crea nuevas convenciones sociales en muchas ocasiones opuestas al individualismo de la frontera. El precio que hay que pagar, sin embargo, por este incremento en el bienestar de la población es la aparición de problemas de índole político y social. La frontera no conllevaba ninguna filosofía social, sino un individualismo anárquico, de tal forma que el pionero era inocente en asuntos de política o de moralidad. La complejidad de la nueva sociedad americana crea una necesidad de buscar la frontera como vía de escape de todo lo erróneo de esta nueva sociedad, elementos que acabarán llevando a Estados Unidos a un periodo de guerras separadas por una depresión económica que afectará a un porcentaje muy elevado de la población. La frontera se convierte, por tanto, en ese emplazamiento romántico, de añoranza de un pasado basado en la libertad y en el individualismo. El ratón Ignatz es un ejemplo de ese individualismo. Ignatz se mueve con absoluta libertad por el territorio del condado de Coconino y no se plantea la moralidad de sus actos, ni siquiera cuando agrede a Krazy. Un gesto tan violento como el lanzamiento del ladrillo que repetidamente realiza Ignatz a la cabeza de Krazy, se transforma en esta serie en algo inocente, un juego de flirteo que supone un canto a la libertad de otra época, la de la frontera, en el que las convenciones sociales estaban por debajo de la libertad individual. No es casual que muchas de las páginas dominicales de la serie acaben con Ignatz encarcelado por parte del perro policía Bull Pup. El romanticismo de la frontera se ve invadido por las convenciones sociales, las reglas morales, cuyo resultado evidente es la privación de libertad del pionero americano que, en ocasiones con un comportamiento cuestionable, pero siempre guiado por esa búsqueda de la libertad, fue el que construyó el país tal y como la sociedad norteamericana de la época lo conoce. La aparición de un nuevo modelo social, con las ventajas evidentes que supone, trae también muchos problemas entre los que la falta de libertad (representada de forma recursiva por el encarcelamiento de lgnatz) es uno de los más importantes. En los momentos en que estos problemas afloran, la añoranza de la frontera, del tiempo pasado, aflora como un elemento fundamental de la narrativa. 


\section{La cotidianeidad en la tira de prensa}

Hasta ahora se ha tratado fundamentalmente series cuyo medio fundamental de expresión era la página dominical, que, si consideramos el origen en The Yellow Kid, fue el formato donde se publicaron los primeros cómics. Sin embargo, a partir del año 1907 con la serie Mutt and Jeff de Bud Fisher, publicada en el San Francisco Chronicle, aparece la tira diaria, publicada en blanco y negro de lunes a sábado en formato de tres a cinco viñetas en forma de tira. En un medio en el que como afirma Trabado, en una idea de origen claramente benjaminiano, "ese mismo formato ofrece un cauce de representación que condiciona las posibilidades expresivas" (2012: 9), la aparición de la tira diaria condiciona la narrativa del cómic norteamericano. Ya no se trata de un cómic que aparece en una sección aparte del periódico que se puede separar totalmente del mismo para dársela a los niños, sino que aparece inserta entre las noticias de los periódicos con un destinatario claramente adulto que es quien leía esas páginas, por su ubicación y por el hecho de que, generalmente, en los días de trabajo, los niños no tenían acceso al periódico. Otro elemento fundamental que marcó el desarrollo del cómic es la aparición de las agencias de prensa (syndicates) que se encargaban de distribuir contenidos para los periódicos de todo el país, incluyendo no sólo noticias, sino secciones de entretenimiento como los cómics. La aparición de estas agencias cambió totalmente el panorama del cómic, ya que la ciudad dejó de ser importante, de tal manera que las series se publicaban en cientos de periódicos en todo el país, de forma que había que recurrir a temas de interés nacional, evitando contenidos de tipo local, especialmente aquellos que pudieran causar controversia en otras partes del país.

Estas dos consideraciones, la aparición diaria dirigida a todos los lectores y su difusión nacional cambiaron en cierta medida la temática de muchas series. No es que las series anteriores desaparecieran, de hecho Krazy Kat se publicaba tanto en formato de tira diaria como de página dominical, pero sí que se percibe un interés por la aparición de series que reflejen de una forma más acusada la cotidianeidad de la nueva estructura de la sociedad norteamericana. Se trata de mostrar, como afirma Waugh que, en cierta manera, "la información que se maneja es real" (1947: 34). Existe una introducción de la temporalidad muy marcada, no sólo en el hecho de que las tiras hacen referencia de vez en cuando a fechas especiales, como Navidades o festividades como el 4 de julio, lo cual ya les da un marco temporal, sino que por ejemplo en la serie Mutt and Jeff mencionada antes en la tira del 29 de marzo de 1908, Fisher hace que su personaje visite una institución para discapacitados mentales donde se hace una imitación de un juicio que se estaba realizando en San Francisco en aquella época. La crítica a las instituciones es clarísima y el hecho de tratarse de una tira sindicada, hace que tenga una repercusión nacional. No será un ejemplo aislado, como demostrarán los comentarios posteriores a la llegada de Herbert Hoover a la presidencia. Ejemplos como estos son numerosos en la series de prensa de esa época. 
Sin embargo, la muestra más palpable de la inmersión del cómic de prensa en la cotidianeidad, es la aparición de series que reflejan la clase media norteamericana y la búsqueda de lo que en esa época se empieza a denominar el modo de vida americano, sobre todo ligado a la predominancia de series donde se muestra la adaptación a la vida urbana y el contraste entre la vida rural y la nueva tendencia hacia la urbanización. Una de las primeras muestras de esta tendencia es la aparición de tiras que reflejan el nuevo modelo matrimonial americano, que culminará en el éxito de Blondie, ya en los años 30, especialmente tras su matrimonio y su estabilización familiar que llevarán a la tira a su consolidación como la más leída por los norteamericanos de la época. Pero antes de eso, se debe hablar de una serie como Bringing Up Father de George McManus que se empieza a publicar en 1913, que por un lado es un canto a las ventajas de lo simple y cotidiano, pero por otro lado es una crítica ácida a la imagen idílica del matrimonio americano y, sobre todo, a la persecución del sueño americano. Bringing Up Father cuenta la historia de un matrimonio de clase humilde, Maggie y Jiggs, que se hacen repentinamente millonarios, lo cual hace cambiar su vida radicalmente. No es casualidad que Jiggs sea un inmigrante irlandés que, claramente, en un golpe de fortuna ha alcanzado el sueño americano de llevar una vida acomodada sin tener que preocuparse de la sostenibilidad económica familiar. Sin embargo, la serie narra continuamente las tensiones matrimoniales basadas fundamentalmente en la añoranza por parte del marido de llevar una vida más simple, una vida en la que pueda disfrutar de los placeres sencillos como una partida de cartas con sus amigos de siempre, sin tener que interrumpirla por tener que asistir a la ópera o a una de las fiestas que organiza su mujer. Las tensiones entre la vida sencilla y la nueva configuración urbana que estaba absorbiendo la sociedad norteamericana se pone de manifiesto constantemente entre este matrimonio, cuyo concepto del sueño de vida americano difiere considerablemente. Esta diferencia es un reflejo de las diferentes necesidades respecto a la configuración de un modelo de vida que existían en la sociedad norteamericana de la época, donde el contraste entre las grandes ciudades con sus complejidades morales y políticas y la realidad rural, mucho más sencilla y aparentemente más bucólica convivían con la tensión inherente a dos configuraciones por un lado tan opuestas, pero por otro condenadas a convivir, como sucede en el matrimonio de Jiggs y Maggie. La Figura 7 muestra una página de Bringing Up Father. La tensión entre el mundo de la elegancia propia de la clase social a la que pertenecen los personajes con los deseos reales del protagonista masculino es evidente. Se atraviesa todo un mundo de elegancia y sofisticación para lograr el objetivo real: la sencillez de una partida de cartas. Si echamos la vista atrás a la Figura 1, se puede ver como la partida de cartas ya aparecía en las páginas de The Yellow Kid, como entretenimiento del chico de barrio, asociado por tanto a la clase baja. 


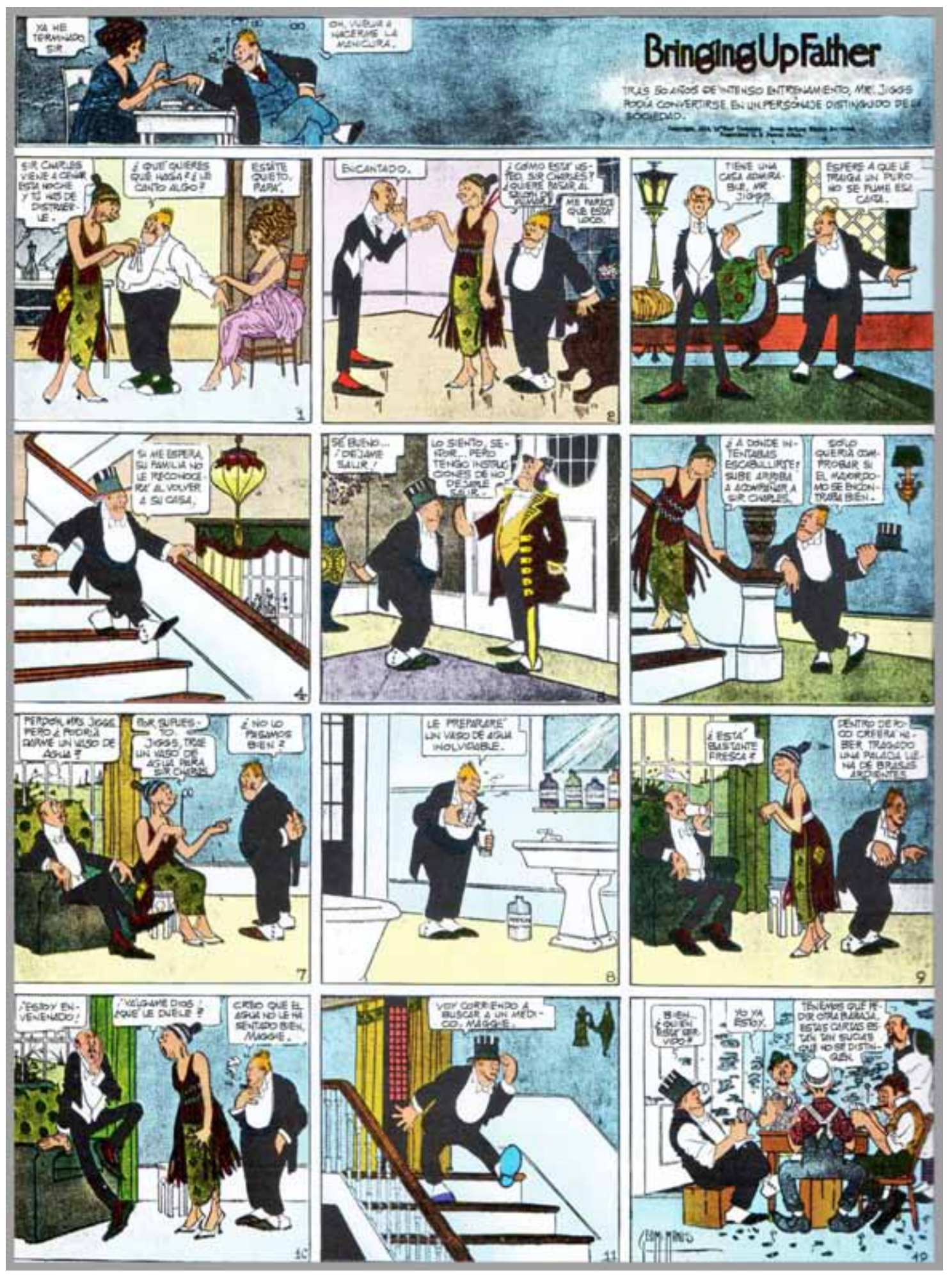

Figura 7. Página dominical de Bringing Up Father del 13 de octubre de 1918.

Esta tensión se manifiesta de mayor manera, cuando el modelo de vida urbana colapsa económicamente en la Gran Depresión. En una época de grandes problemas económicos, en lo que se refiere a las tiras cotidianas aparecen dos tendencias que se pueden ejemplificar en dos de las series más exitosas de esos años, la ya mencionada Blondie y Li'l Abner. Por un lado, en Blondie, creado por Chic Youg en 1930, tenemos la 
tendencia a la amabilidad que apareció en gran parte de la cultura americana, reflejada en la aparición en la radio o en el cine de numerosas comedias que, a veces con un trasfondo crítico, buscaban resaltar la tranquilidad de la vida del americano medio y de la familia americana media, en la que el personaje en ocasiones es humillado, pero que al final consigue las comodidades del modo de vida americano. La relación sentimental y, posterior matrimonio de Dagwood y Blondie es un ejemplo de visión amable de la vida en la que, pese a las evidentes carencias de Dagwood (un personaje que se escaquea del trabajo, obsesionado por los deportes y la comida basura), al final no es más que un reflejo del americano medio que consigue encontrar la felicidad en el seno de esa familia americana media, mostrando el después de comedias como Sucedió una noche de Frank Capra, donde personajes condenados a no entenderse finalmente encuentran el amor. Blondie sería el vivieron felices tras ese encuentro amoroso. Blondie es el después del happy end de las comedias románticas de la época. Un reflejo de un modelo que trataba de resurgir ante las condiciones adversas económicas y que, como manifiesta Susman, será el centro de la New York's Fair de 1939 y 1940, donde se comienza a configurar un modelo de familia americana del mañana, del que Blondie es un claro ejemplo. Esta idea de configurar un modelo de la sociedad norteamericana se pone de manifiesto en el hecho que ese mismo año 1939, Gallup empieza a realizar las primeras encuestas sobre comportamientos y aficiones de la población, donde se trata de cuantificar las tendencias de la población. Estos estudios ayudan a la configuración de un modelo familiar que, con sus crisis, pervive hasta nuestros días y que explica el porqué del éxito de una serie como Blondie que todavía se continua publicando y que creará una tendencia que llegará también al cómic-book, donde un cómic como Archie será durante mucho tiempo el más vendido en los kioskos norteamericanos con un modelo de americano medio muy similar al creado en Blondie. La Figura 8 muestra la cotidianeidad del mundo de Blondie, el marido vuelve a casa para arrojarse en los brazos de su esposa y en la comida que ésta le ha estado amorosamente preparando.

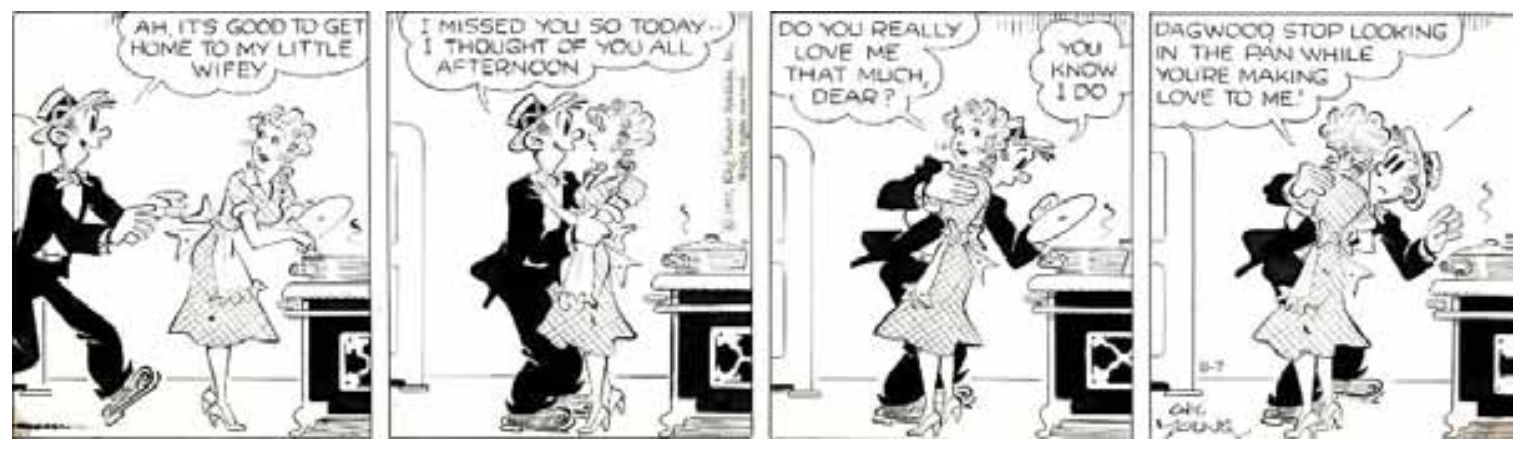

Figura 8. Tira diaria de Blondie del 7 de agosto de 1938. 
La otra tendencia en el cómic es la preconizada por Li'l Abner, credo en 1934 por Al Capp. En este caso hay un mayor interés en subrayar las tensiones entre las clases sociales, y especialmente entre el mundo rural y el mundo urbano estadounidense. Li'| Abner es un campesino de mentalidad simple que vive en el tranquilo pueblo de Dogpatch y que, por diversas circunstancias, se traslada en ocasiones a Nueva York, entre otras cosas para aumentar su status social y su formación intelectual. El contraste entre la vida rural de Dogpatch, donde prácticamente no existe maldad y, donde, cuando aparece algún personaje que realiza alguna artimaña, ésta está basada en la inocencia, en contraposición con las maquinaciones de los pobladores de la gran ciudad se acentúa (Berger, 1994; Schumacher, 2013). La ignorancia de Li'l Abner le hace infeliz en Nueva York, pero, sin embargo, es más que suficiente para alcanzar una vida plena en el entorno tranquilo de Dogpatch. Existe un contraste claro entre las necesidades que la sociedad consumista urbana ha creado respecto a las que una sociedad rural necesita para llevar una vida plena. La sociedad de consumo que ha llevado al colapso económico y a una época de depresión que, hasta ese momento no tenía parangón en la historia norteamericana, se demuestra claramente como un modelo que hace aflorar los peores sentimientos del ser humano y que no conlleva la felicidad. La añoranza del mundo rural de Li'l Abner es, en cierta manera, similar a la añoranza de la frontera que aparece en Krazy Kat, de un mundo más sencillo, donde no son necesarias las complicaciones de las nuevas estructuras sociales. Es especialmente destacable un episodio como el del divorcio de los padres de Li'l Abner, al comienzo de la serie, donde se ven obligados a divorciarse por las maquinaciones de una especie de abogado que sólo busca obtener un beneficio económico de dicho divorcio. Sin embargo, una vez divorciados siguen felices como pareja. No se puede considerar el mensaje de esta historia como conservador, porque es una crítica no sólo al divorcio, sino también al matrimonio (la negación del personaje de Li'l Abner al matrimonio sería otro ejemplo), ya que ambas son simplemente convenciones sociales que, al final, condicionan el desarrollo del individuo que, por sí mismo, es capaz de encontrar la felicidad. Existe, por tanto, una lucha en la sociedad norteamericana de la época, fruto de las tensiones de la depresión, entre un modelo de sociedad de consumo, personificado en Blondie o un modelo de retorno al individualismo, personificado en Li'l Abner que la Segunda Guerra Mundial y la creación de una economía de guerra hará decantarse por la sociedad urbana y de consumo que conocemos hoy en día, lo cual no impedirá cierta añoranza que hará que series como Li'l Abner pervivan en el tiempo. La Figura 9 muestra una página dominical de Li'l Abner donde el contraste entre el mundo urbano y el rural es evidente en los dos personajes femeninos. La sofisticada mujer urbana adquiere una connotación negativa en comparación con la paciencia y la comprensión de la más sencilla mujer rural. 


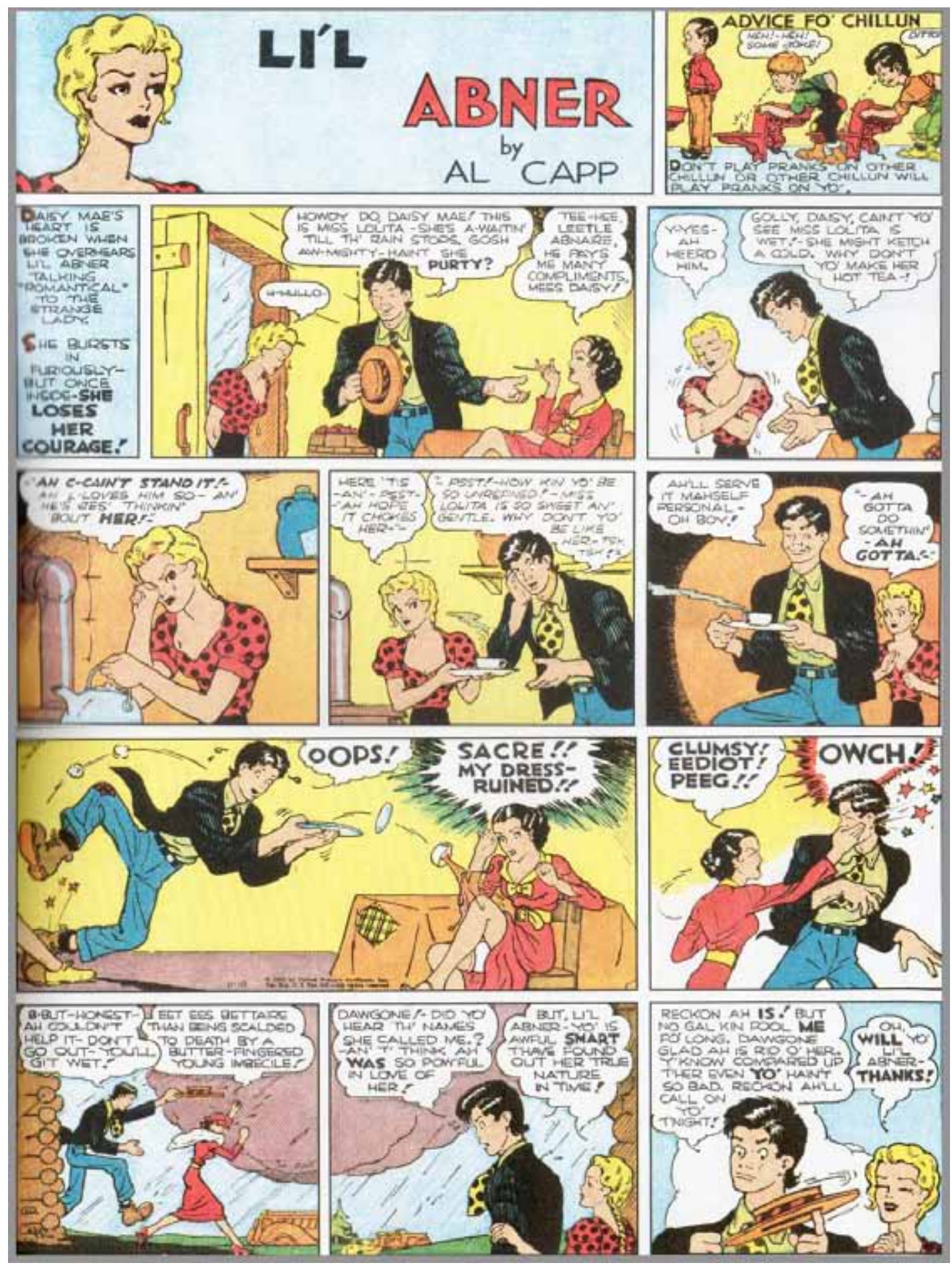

Figura 9. Página dominical de Li'l Abner del 10 de noviembre de 1935.

Finalmente, si hablamos de la cotidianeidad, el ejemplo más importante en las tiras de prensa, es Gasoline Alley creada en 1918 por Frank King. King introduce un aspecto pionero en las series de prensa y es la temporalidad. Nos enseña, como afirma Iván Pintor, "que los personajes de cómic pueden envejecer" (2014). Esto hace que esta sea una serie fundamental para estudiar el devenir de la sociedad norteamericana de la época. La relación entre Walt, el personaje central de los primeros años, y Skeezix, el niño que se encuentra abandonado y decide adoptar, rodeados de los personajes que 
bien en su barrio y en el taller mecánico en el que trabaja Walt son posiblemente el primer slice of life del cómic norteamericano y, como tal, una muestra constante de las inquietudes de la sociedad de la época como se puede ver en (Gordon, 1998). Por las páginas de Gasoline Alley veremos pasar la obsesión por la tecnología y por el automóvil de la primera época, los estragos de la Gran Depresión, la llegada de la guerra y como todos estos acontecimientos afectan a los personajes. Veremos, al fin y al cabo, el paso del tiempo, como muestra la página de la Figura 10 donde se manifiesta la llegada del otoño y cómo afecta a nuestros personajes. Frank King es capaz de mostrar la influencia de algo tan cotidiano como el paso de una estación, logrando la misma maestría para otros sucesos más transcendentes de la vida norteamericana.

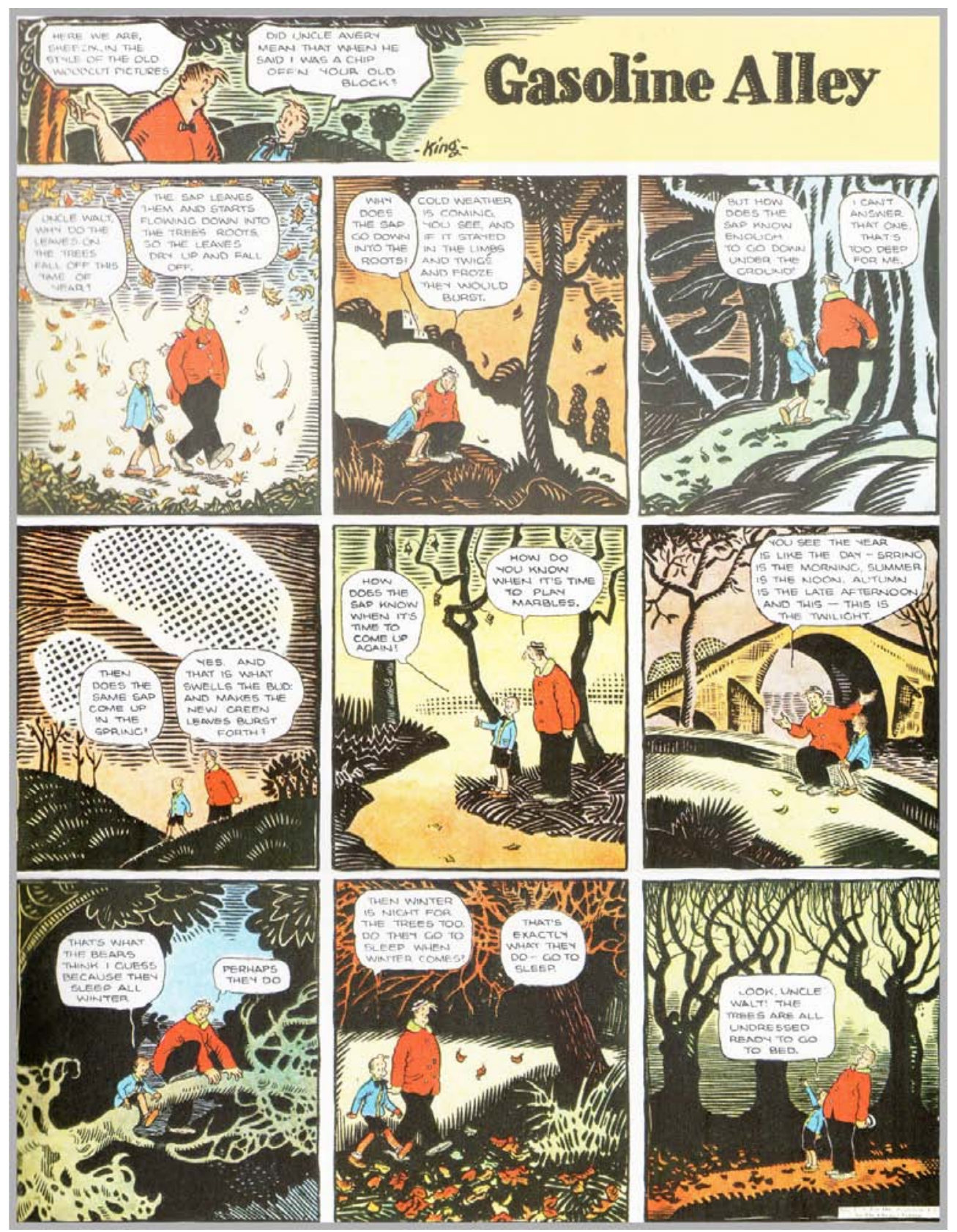

Figura 10. Página dominical de Gasoline Alley del 30 de noviembre de 1930. 
Todos los elementos recogidos en este capítulo pueden encontrarse en un momento u otro en Gasoline Alley. Como afirma Coulton Waugh, no hay mejor imagen de la juventud americana en 1942 que el episodio de Gasoline Alley cuando Skeezix se encuentra en frente de una señal que dice Oficina de Reclutamiento. Millones de americanos, "viendo a Skeezix en el norte de África, con un casco sobre su cabeza amistosa y juvenil, entendieron que estábamos realmente en guerra, y sintieron que el personaje era un símbolo de algo puro, limpio y silenciosamente determinado" (Waugh, 1947: 96). El cómic como imagen de la actitud de todo un país ante un suceso trascendental como una guerra mundial. La Figura 11 muestra una de las tiras que cuentan las vicisitudes de Skeezix en la II Guerra Mundial.
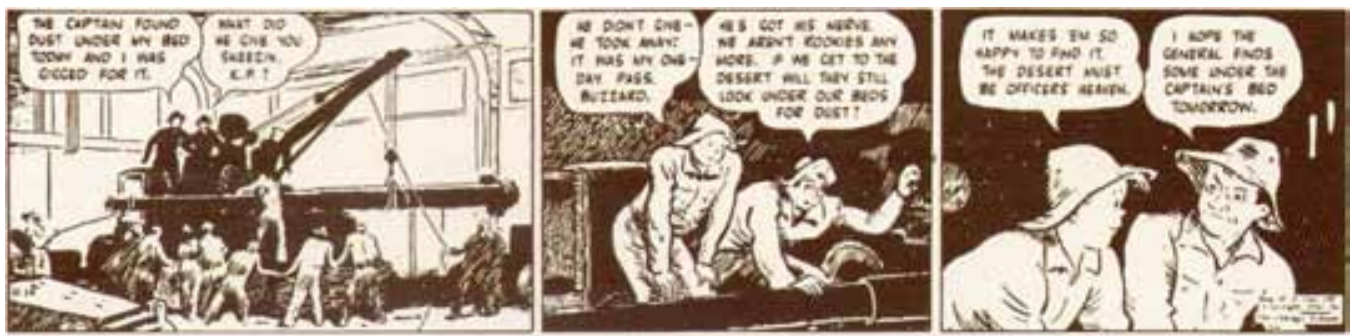

Figura 11. Tira diaria de Gasoline Alley del 2 de octubre de 1942.

\section{El nacimiento del héroe en el serial de aventuras}

A pesar de lo mencionado anteriormente la mayor aportación (por decirlo de alguna manera) de la Gran Depresión al cómic de prensa es la aparición del héroe de aventuras. No es casualidad que 1929 sea el año donde aparecen tres personajes que inauguran una tendencia en el cómic de prensa que reportará un gran éxito. Es por un lado la aparición de Popeye, creado por Segar, en la serie cómica Thimble Theatre, la adaptación de Tarzan al cómic realizado por Hal Foster o la creación de Buck Rogers por Philip Francis Nowlan, que inaugura el serial de ciencia ficción en los cómics. Existe como reconoce Robert S. McElvaine una necesidad de escapismo, de aventura, que ya aparece en los seriales de radio o cinematográficos y, que el modelo de continuidad de la tira diaria, acoge con gran naturalidad. Puede parecer discutible la incursión de Popeye en esta lista, ya que tradicionalmente se incluye más en los personajes de corte cómico. Sin embargo, sin querer negar la comicidad del personaje, tal y como afirma Waugh, Popeye es un precursor en el renacer de la figura masculina en el cómic que dará origen al héroe de aventuras. Un héroe que tendrá como los personajes de John Ford un fuerte componente de clase como resultado de las desigualdades 
sociales creadas por la Depresión. No es casual que entre los personajes de La Diligencia, la única persona que no es justa ni benévola, sea el egoísta banquero y que el resto de los personajes tengan un componente de compasión pese a su condición de fuera de la ley, jugador o prostituta. "I yam what I yam an' tha's all I yam!" afirma Popeye como expresión definitiva, no solo de su masculinidad, sino también de su condición de persona del pueblo dispuesta a luchar contra cualquier injusticia que se presente. Segar, además, introduce un elemento en las tiras de prensa como es el suspense, fundamental para el desarrollo del serial de aventuras.

Con esta perspectiva, aparecen personajes como los Tarzan y Buck Rogers, mencionados antes a los que luego se unirán otros como Flash Gordon creado por Alex Raymond en 1934, The Phantom creado en 1936 por Lee Falk y Ray Moore o Secret Agent X-9 creado en 1934 por Dashiell Hammett y el propio Alex Raymond entre los más importantes. En este género del serial de aventuras se encuentra una serie como Terry y los Piratas de Milton Caniff creada en 1936 y en cuyos comienzos el personaje de Pat Ryan y el mismo Terry cuando empieza a crecer, son un ejemplo claro de este héroe de aventuras que lucha contra las injusticias poniéndose siempre de parte del oprimido como corresponde a una sociedad cada vez más consciente de la diferencia de clases creada por la Gran Depresión. Pero sería injusto centrar el nacimiento de este modelo de héroe en la Gran Depresión, ya que también es un claro heredero del héroe acrobático que definen Nuria Bou y Xavier Pérez, creado fundamentalmente para los seriales cinematográficos, con anterioridad al año 1929 (Bou y Pérez, 2000). Por tanto, lo que hace la Gran Depresión, es añadir a ese arquetipo heroico una componente social propia de la época, además de aprovecharse de una necesidad de escapismo que hará proliferar ese tipo de héroes en los cómics. Pero como afirma Susman, siendo el escapismo un factor, hay que ver por qué la gente escoge escaparse de la manera que lo hace. El componente social del héroe de aventuras del cómic aparece de forma reiterada como consecuencia de las circunstancias sociales de la época.

Otro aspecto importante de la sociedad norteamericana que refleja el serial de aventuras es la necesidad de la creación de mitos. Muchos autores han destacado el carácter mitológico de los superhéroes (Jewett y Lawrence, 2002; Waid, 2010) y su configuración como una moderna mitología norteamericana. No es un aspecto totalmente ajeno a este trabajo, ya que se trata de creaciones de cómics, pero al tratarse de personajes que aparecen en el cómic-book, se escapa del marco del cómic de prensa $y$, por este motivo, es más interesante comentar un personaje como The Phantom, reconocido por muchos como el precursor de los superhéroes. The Phantom es un héroe enmascarado que, aunque no posee superpoderes, tiene unas habilidades atléticas que lo destacan por encima del ser humano y lo emparejan en cierta manera con el superhéroe del cómic-book del que es precursor. The Phantom vive sus aventuras en el momento actual, pero es el número 21 de un linaje, en el que el primer 
varón de la familia se dedica a luchar contra la injusticia, tradición que va pasando del progenitor a su vástago tras la muerte de aquel. Esta tradición que se remonta a los tiempos del descubrimiento de América cuando el primer fantasma fue atacado y casi ejecutado por una banda de piratas, se articula de tal manera que el manto del fantasma pasa de un personaje a otro, sin que nadie, excepto los involucrados, sea consciente de que el fantasma anterior ha muerto. Por tanto, la creencia general es la de la inmortalidad del personaje, de tal forma que cuando un hijo toma el puesto de su padre, el villano que ha acabado con su vida cree que el fantasma ha vuelto de la tumba. Este mecanismo, por lo demás no muy explotado en la serie, le confiere el carácter mítico al personaje que será básico para la creación de un tipo de narrativa eminentemente norteamericano. $Y$ es muy pertinente este trabajo, por su enlace evidente con la historia. Pese a que The Phantom vive en África, el personaje nace con el descubrimiento de América, de tal forma que ese carácter indestructible y su perdurabilidad frente al mal y la injusticia es un reflejo de la fortaleza de un país (no olvidemos que a los estadounidenses les gusta apropiarse del término de americanos), cuyo modelo perdurará pese a los obstáculos y las injusticias que puedan aparecer. Un tema muy propio de la Gran Depresión, por otra parte, ya que como dice el propio Tom Joad en la obra más representativa de esa época de la historia norteamericana "allí donde haya una lucha contra la sangre y el odio en el mundo, mírame allí mamá porque allí estaré" (Steinbeck, 1975). Al fin y al cabo no muy alejado del juramento del fantasma "juro dedicar toda mi vida a la destrucción de la piratería, la codicia, la crueldad y la injusticia en todas sus formas". Añadiendo el componente aventurero de la piratería, se trata de un patrón que definirá un modelo que al final perdurará en el tiempo y configurará toda una mitología como es la del superhéroe norteamericano. La Figura 12 muestra el juramento contra la injusticia de The Phantom.

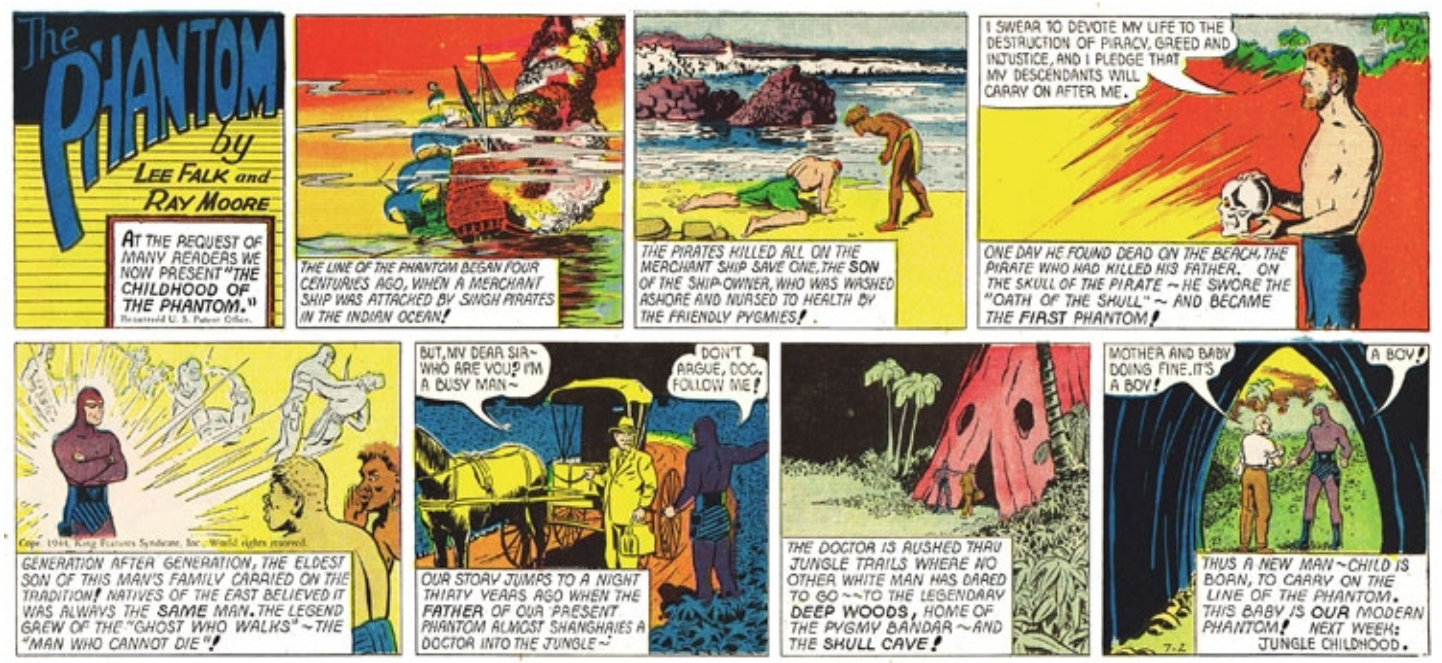

Figura 12. Página dominical de The Phantom del 2 de julio de 1944. 


\section{Conclusiones}

En este artículo se ha analizado el papel de las tiras de prensa norteamericanas como imagen de la historia y, especialmente, de la sociedad estadounidense de los años 30 y 40, época dorada del cómic de prensa como medio de comunicación que llegaba a millones de lectores, ligado siempre al periódico, lo que convertía la actividad de la lectura de este tipo de cómic en algo cotidiano y, además, fuertemente ligado a la actualidad. Se ha analizado cómo las tiras de prensa incorporan elementos que permiten analizar las principales inquietudes y acontecimientos de una sociedad que, por otro lado, estaba en plena construcción en dicha época. La aparición de una sociedad urbanita en contraposición con la conquista de la frontera que había constituido la base sobre la que se había construido el país, se refleja en las tensiones entre campo y ciudad, así como en la añoranza de la libertad asociada a la frontera, que aparecen en muchas de las series de prensa de la época. También la aparición de la clase media en forma del trabajador que vive en los suburbios y se desplaza cada día a la ciudad para trabajar, encuentra su reflejo en este medio de expresión. Finalmente, estos años están fuertemente marcados por el colapso económico que supone la Gran Depresión, aspecto que también tendrá su reflejo en varios aspectos, fundamentalmente, en la aparición del serial de aventuras.

\section{Referencias bibliográficas}

APOSTOLIDES, J.M. et al. (2005). Little Nemo 1905-2005. Un siglo de sueños. Madrid: Editorial Sinsentido.

BARRERO, M. et al. (2013). La Novela Gráfica. Poéticas y Modelos Narrativos. J. M. Trabado (ed.). Madrid: Arco Libros.

BENJAMIN, W. (1973). Discursos Interrumpidos 1. Madrid: Taurus Ediciones.

BERGER, A.A. (1994). Li'l Abner: a Study in American Satire. Mississipi: University Press of Mississippi.

BLACKBEARD, B. (1984). "Niños, Capitanes y Sombreros de Hojalata". Historia de los Cómics, vol. 1. Barcelona: Toutain.

BOU, N. Y PÉREZ, X. (2000). El Tiempo del Héroe. Épica y Masculinidad en el Cine de Hollywood. Barcelona: Paidós.

CAMPBELL, W. J. (2006). The Year that Defined American Journalism: 1897 and the Clash of Paradigms. New York: Taylor \& Francis. 
COSTELLO, M. J. (2009). Secret Identity Crisis. Comic books \& the Unmasking of Cold War America. Londres: Bloomsbury Academic.

FRANK, W. (1929). The Rediscovery of America: An Introduction to a Philosophy of American Life. New York: Charles Scribner's Sons.

FREZZA, G. (2009). "Guerras y Posguerras: la Visión Política del Futuro en la Ciencia Ficción de los Cómics, Películas y Series Contemporáneas" en Formats: Revista de Comunicació Audiovisual, no 5, Enero de 2009.

GORDON, I. (1998). Comic Strip and Comsumer Culture 1890-1945. Washington y Londres: Smithsonian Institution Press.

GUIRAL, A. (2007-2013). Del Tebeo al Manga. Una Historia de los Cómics. Volumen 1. Barcelona: Panini Cómics.

GRÉGORIO, P. P. (2007). "Dátile y los Españoles de la Transición frente a las Primeras Elecciones" en Humor y Sociedad en el Mundo Hispánico Contemporáneo. Nanterre: Université de Paris-10.

HAMPTON, M. (2013). “The Political Cartoon as Educationalist Journalism: David Low's Portrayal of Mass Unemployment in Interwar Britain" en Journalism Studies, vol. 14, no 5, Diciembre de 2013.

HARVEY, R.C. (1994). The Art of Funnies: An Aesthetic History. Mississippi: University of Mississippi Press.

- (2009). "How Comics Come to be" en A Comic Reader. Jeet Heer (ed.). Mississippi: University Press of Mississippi, 2009.

HORN, M. (1984). "El Nacimiento de los Cómics Norteamericanos". Historia de los Cómics, vol. 1. Barcelona: Toutain.

HUGHES, T.P. (1989). American Genesis. A Century of Invention and Technological Enthusiasm. New York: Penguin Group.

LAWRENCE, J. S. Y JEWETT, R. (2002). The Myth of the American Superhero. Grand Rapids: Eerdmans.

LINDSAY, V. (1915). The Art of the Moving Picture. Nueva York: The MacMillan Company.

MCELVAINE, R. (1984). The Great Depression. America 1929-1941. New York: times Books.

MUMFORD, L. (1938). The Culture of Cities. Nueva York: Harcourt, Brace \& Co. 
PEÑAMARÍN, C. (2002). "El Humor Gráfico del Franquismo y la Formación de un Territorio Translocal de Identidad Democrática" en CIC Cuadernos de Información y Comunicación, no 7, Enero de 2002.

PINTOR, I. (2014). "El Sueño y la Historia: Las Distancias entre el Cine y el Cómic Documental". ShangriLa. Aceptado para su publicación.

RODRÍGUEZ MORENO, J. J. (2010). Los Cómics de la Segunda Guerra Mundial: Producción y Mensaje en la Editorial Timely (1939-1945). Cádiz: Servicio de Publicaciones de la Universidad de Cádiz.

SÁNCHEZ ARANDA, J. J. (1998). Pulitzer. Luces y Sombras en la Vida de un Periodista genial. Pamlona: EUNSA.

SCHUMACHER, M. Y KITCHEN. D. (2013). Al Capp: A Life to the Contrary. New York: Bloomsbury Academics.

SMOLDEREN, T. (2009). Naissance de la Bande Desssinée. Bruselas: Les Impressions Nouvelles.

STEINBECK, J. (1975). The Grapes of Wrath. Pennsylvania: The Franklin Library. Primera edición de 1940.

STERANKO, J. (1970). The Steranko History of Comics, 2 vols. New York: Supergraphics.

SUSMAN, W. I. (1987). La Cultura como Historia. México: EDAMEX.

TRABADO, J. M. (2012). Antes de la Novela Gráfica. Clásicos del Cómic en la Prensa Norteamericana. Madrid: Cátedra.

WAID, M. (2010). "La Auténtica Verdad sobre Superman (y sobre Todos Nosotros)". Los Superhéroes y la Filosofía. Barcelona: Blackie Books.

WAUGH, C. (1947). The Comics. New York: MacMillan.

WHYTE, K. (2009). The Uncrowned King: The Sensational Rise of William Randolph Hearst. Random House LLC. 